\title{
Anti-brain Antibodies in PANDAS Versus Uncomplicated Streptococcal Infection
}

\author{
Piero Pavone, MD*, Rio Bianchini, MD*, Enrico Parano, $\mathbf{M D}, \mathbf{P h D}^{\dagger}$, \\ Gemma Incorpora, MD*, Renata Rizzo, MD*, Luigi Mazzone, MD*, and \\ Rosario R. Trifiletti, MD, PhD*
}

The objective of this study was to assess brain involvement through the presence of antineuronal antibodies in Pediatric Autoimmune Neuropsychiatric Disorders Associated with Streptococcus (PANDAS) and in uncomplicated active Group A streptococcal infection. We compared serum antibrain antibody to human basal ganglia sections assessed by indirect tissue immunofluorescence in two groups: a PANDAS group, comprised of 22 patients (mean age 10.1 years; 20 male, 2 female) who met strict National Institutes of Mental Health diagnostic criteria for PANDAS and had clinically active tics or obsessive-compulsive disorder, or both; and a GABHS control group consisting of 22 patients (mean age 9.1 years; $15 \mathrm{~mol} / \mathrm{L}, 7$ female) with clinical evidence of active Group A $\beta$-hemolytic streptococcal (GABHS) infection confirmed by throat culture and elevated antistreptolysin $O$ titers but without history or clinical evidence of tics or obsessivecompulsive disorder. We observed positive anti-basal ganglia staining (defined as detectable staining at 1:10 serum dilution) in 14/22 patients in the PANDAS group $(64 \%)$ but only $2 / 22(9 \%)$ in the GABHS control group $(P<0.001$, Fisher's exact test $)$. These results suggest that antibrain antibodies are present in children with PANDAS that cannot be explained merely by a history of GABHS infection. (C) 2004 by Elsevier Inc. All rights reserved.

Pavone P, Bianchini R, Parano E, Incorpora G, Rizzo R, Mazzone L, Trifiletti RR. Anti-brain antibodies in PANDAS vs uncomplicated streptococcal infection. Pediatr Neurol 2004;30:107-110.

From the *Division of Pediatric Neurology, University of Catania, Catania, Italy; ${ }^{\dagger}$ Institute of Neurological Science, The National Research Council of Italy-CNR, Catania, Italy; and *Departments of Neurology and Pediatrics, Saint Vincent's Hospital, New York

Medical College, New York, New York.

\section{Introduction}

The presence of features of tics, Tourette syndrome, or obsessive-compulsive disorder in the context of an immediately precedent streptococcal infection has led Swedo et al. [1,2] at the National Institutes of Mental Health to propose the general concept of Pediatric Autoimmune Neuropsychiatric Disorders Associated with Streptococcus (abbreviated by the acronym PANDAS). The PANDAS concept emphasizes the range of clinical neuropsychiatric symptoms [2] that may be observed in a given patient.

The diagnosis of PANDAS requires a prospectively determined association between Group A beta-hemolytic streptococcal (GABHS) infection and obsessive-compulsive disorder or tic disorder.

As has been reported for Sydenham's chorea, also for PANDAS, antibrain (and more specifically antibasal ganglial) antibodies have been demonstrated in the serum $[2,3]$. It is possible that these antibrain antibodies represent antibodies that are formed as a direct result of a normal response to GABHS infection, i.e., representing spurious cross-reactivity with streptococcal antigens. If this were the case, then patients with GABHS pharyngitis, but without PANDAS, might be expected to display such antibrain antibodies in the blood. Furthermore, if this were the case, it would make such antibodies unlikely to be involved in the pathophysiology of PANDAS.

The objective of the present study was to examine the frequency of antibrain antibody in patients with PANDAS as a consequence of direct brain involvement, compared with those with documented GABHS infection, but without neuropsychiatric symptoms.
Communications should be addressed to:

Dr. Pavone; Department of Pediatric Neurology; University of Catania; Via S. Sofia 78; 95125 Catania, Italy.

Received February 13, 2003; accepted June 19, 2003. 


\begin{tabular}{|c|c|c|c|c|c|c|}
\hline $\begin{array}{l}\text { Patient } \\
\text { No. }\end{array}$ & Sex & Age & $\begin{array}{l}\text { Anti-streptolysin } O \text { titers } \\
\text { (Normal value: }<250 \mathrm{U} / \mathrm{I} \text { ) }\end{array}$ & $\begin{array}{l}\text { Antideoxyribonuclease B } \\
\text { (Normal value: < } 250 \mathrm{U} / \mathrm{I} \text { ) }\end{array}$ & $\begin{array}{l}\text { Antineuronal Antibodies } \\
\text { (Normal value: < 1/10) }\end{array}$ & $\begin{array}{l}\text { Interval Between the } \\
\text { Onset of Disease and the } \\
\text { Assay of Antibody } \\
\text { (Mean duration: } 51 \text { days) }\end{array}$ \\
\hline 1 & M & 12 & 54 & 207 & neg & 45 \\
\hline 2 & M & 9 & 400 & 650 & $1 / 40$ & 67 \\
\hline 3 & M & 10 & 374 & 306 & neg & 73 \\
\hline 4 & M & 11 & 306 & 124 & $1 / 10$ & 21 \\
\hline 5 & M & 14 & 532 & 664 & $1 / 40$ & 90 \\
\hline 6 & M & 7 & 150 & 263.6 & $1 / 20$ & 32 \\
\hline 7 & M & 15 & 280 & 376.1 & neg & 12 \\
\hline 8 & M & 14 & 106 & 203 & $1 / 40$ & 79 \\
\hline 9 & M & 12 & 358 & 287 & $1 / 100$ & 82 \\
\hline 10 & M & 8 & 600 & 983 & $1 / 80$ & 3 \\
\hline 11 & M & 10 & 864 & 1499 & $1 / 100$ & 57 \\
\hline 12 & M & 9 & 168 & 1027 & $1 / 100$ & 66 \\
\hline 13 & M & 11 & 215 & 450 & $1 / 20$ & 39 \\
\hline 14 & M & 9 & 370 & 54 & neg & 25 \\
\hline 15 & $\mathrm{M}$ & 9 & 62 & 37 & $1 / 10$ & 63 \\
\hline 16 & $\mathrm{M}$ & 14 & 120 & 196 & neg & 77 \\
\hline 17 & M & 8 & 612 & 993 & $1 / 20$ & 56 \\
\hline 18 & M & 10 & 375 & 37.8 & neg & 37 \\
\hline 19 & $\mathrm{~F}$ & 9 & 294 & 74.4 & neg & 29 \\
\hline 20 & M & 6 & 54 & 199 & neg & 84 \\
\hline 21 & M & 7 & 291 & 600 & $1 / 40$ & 65 \\
\hline 22 & $\mathrm{~F}$ & 9 & 194 & 297 & $1 / 20$ & 20 \\
\hline
\end{tabular}

Table 1B. Group A $\beta$-hemolytic streptococcal infection tonsillopharyngitis (GABHS)

\begin{tabular}{|c|c|c|c|c|c|c|}
\hline $\begin{array}{l}\text { Patient } \\
\text { No. }\end{array}$ & Sex & Age & $\begin{array}{l}\text { Anti-streptolysin } 0 \text { titers } \\
\text { (Normal value: }<250 \mathrm{U} / \mathrm{I} \text { ) }\end{array}$ & $\begin{array}{c}\text { Antideoxyribonuclease B } \\
\text { (Normal value: < } 250 \text { U/I) }\end{array}$ & $\begin{array}{l}\text { Antineuronal Antibodies } \\
\text { (Normal value: }<250 \text { U/I) }\end{array}$ & $\begin{array}{l}\text { Interval Between the } \\
\text { Onset of Disease and the } \\
\text { Assay of Antibody } \\
\text { (Mean duration: } 19 \text { days) }\end{array}$ \\
\hline 1 & M & 9 & 1309 & 537 & neg & 12 \\
\hline 2 & $\mathrm{M}$ & 8 & 680 & 243 & neg & 14 \\
\hline 3 & $\mathrm{~F}$ & 9 & 591 & 528 & $1 / 40$ & 22 \\
\hline 4 & $\mathrm{~F}$ & 10 & 270 & 186 & neg & 30 \\
\hline 5 & $\mathrm{M}$ & 13 & 120 & 196 & neg & 11 \\
\hline 6 & M & 6 & 299 & 1965 & neg & 16 \\
\hline 7 & M & 14 & 265 & 386 & neg & 10 \\
\hline 8 & $\mathrm{~F}$ & 10 & 63 & 52.5 & neg & 21 \\
\hline 9 & $\mathrm{~F}$ & 11 & 322 & 140.1 & neg & 25 \\
\hline 10 & $\mathrm{M}$ & 7 & 437 & 167 & neg & 26 \\
\hline 11 & $\mathrm{M}$ & 10 & 365 & 221 & neg & 18 \\
\hline 12 & $\mathrm{M}$ & 10 & 183 & 37.8 & $1 / 20$ & 17 \\
\hline 13 & M & 11 & 245 & 548.7 & neg & 19 \\
\hline 14 & $\mathrm{M}$ & 9 & 129 & 429.4 & neg & 13 \\
\hline 15 & M & 8 & 65 & 565.7 & neg & 29 \\
\hline 16 & M & 10 & 213 & 438 & neg & 20 \\
\hline 17 & $\mathrm{M}$ & 9 & 413 & 641 & neg & 13 \\
\hline 18 & $\mathrm{~F}$ & 8 & 255 & 1965 & neg & 11 \\
\hline 19 & $\mathrm{M}$ & 8 & 261 & 389 & neg & 21 \\
\hline 20 & $\mathrm{~F}$ & 6 & 69 & 72.5 & neg & 27 \\
\hline 21 & $\mathrm{~F}$ & 7 & 322 & 140.1 & neg & 25 \\
\hline 22 & M & 7 & 289 & 53 & neg & 18 \\
\hline
\end{tabular}

\section{Materials and Methods}

Our study involved two groups of patients. The first group ("PANDAS group") included 22 patients with an age between 6 and 15 years and mean age of 10.09 ( \pm 2.505$)$, referred to the Day Hospital of Neuro- pediatrics, Division of Pediatrics of the University of Catania in the period from January 1999 to April 2002. All but two in the PANDAS group were male (Table 1A). Diagnosis was established based on National Institutes of Mental Health diagnostic criteria for PANDAS. Additionally, all the patients were studied by electroencephalogram and 
Table 2. Antineuronal antibodies detected in PANDAS and GABHS patients

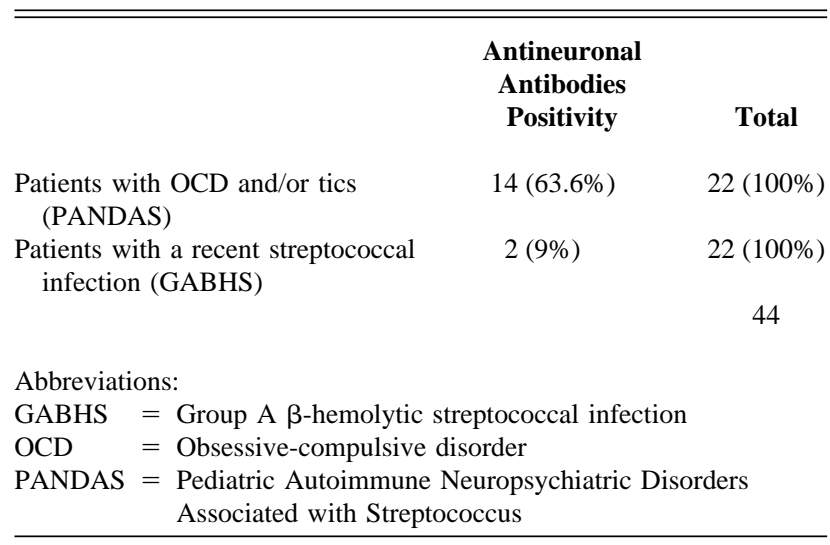

neuroimaging (either head computed tomography or magnetic resonance imaging) which were normal. The second group ("GABHS tonsillopharyngitis"; Table 1B) consisted of 22 patients, with clinical signs of tonsillopharyngitis such as sore throat, fever, and headache. The clinical manifestations had a duration of 2 and 5 days (mean 3 days); seven were female and 15 were male, with ages ranging from 6 to 14 years and mean age of $9.091( \pm 2.18)$. All the patients had evidence of a recent GABHS infection confirmed by throat culture or antistreptolysin $\mathrm{O}$ titers higher than $250 \mathrm{U} / \mathrm{I}$

All the patients were screened using guidelines set forth in the Diagnostic and Statistical Manual of Mental Disorders, Fourth Edition, to exclude other neuropsychiatric disorders, other than attention deficit hyperactivity disorder which is frequently observed as a co-morbid condition in Tourette syndrome. We examined antistreptolysin $\mathrm{O}$ titers, antideoxyribonuclease $\mathrm{B}$, and antineuronal antibodies in all patients in both groups, at an interval of 3 days to several months (mean duration: 51 days) from the onset of neuropsychiatric symptoms in the PANDAS group and 10-30 days (mean duration: 19 days) after the onset of tonsillopharyngitis in the GABHS group without neuropsychiatric symptoms

All the patients with GABHS tonsillopharyngitis were treated with either oral penicillin or other specific antistreptococcal oral antibiotics; no steroids were used. No treatment was initially used in the PANDAS group patients. No new infections were recorded during the study period in either group.

Antineuronal antibodies were determined using human basal ganglia section, according to the method of Husby et al. [3], and scored using criteria described therein.

\section{Results}

Antineuronal antibodies were detected in $63.6 \%$ of the patients of the PANDAS group (14 of 22; Table 2). We detected a high titer of antistreptolysin $\mathrm{O}$ and antideoxyribonuclease $\mathrm{B}$ in $13 / 22$ patients in the PANDAS group, but there was no significant correlation between the presence of antistreptolysin $\mathrm{O}$, antideoxyribonuclease $\mathrm{B}$, and antineuronal antibodies. In the "GABHS pharyngitis" group, i.e., in the patients with a streptococcus infection of recent data, antineuronal antibody staining was detected in 2/22 patients. Statistical analysis using Fisher's exact test indicated a significance $(P<0.001)$ demonstrating that PANDAS and GABHS tonsillopharyngitis differ significantly with respect to the presence of antineuronal antibodies.
In children with tics (PANDAS), a positive correlation between antineuronal antibodies and severity of tic disorder (measured by the Yale Global Tic Severity Scale) was demonstrated.

\section{Discussion}

As reported in Table 2, antineuronal staining was detected in $63.6 \%$ of the PANDAS group, whereas in the GABHS group only $9 \%$ displayed antineuronal antibodies.

Kondo and Kabasawa [4] reported an 11-year-old Japanese male who developed acute onset of vocal and motor tics indistinguishable from those observed in idiopathic Tourette syndrome. These symptoms had an explosive onset approximately 10 days after a recent streptococcal infection. This male failed to respond to conventional tic-suppressing drugs, including haloperidol; he had a rapid and dramatic response to corticosteroid therapy. Matarazzo [5] reported two children who developed acute onset of Tourette syndrome after streptococcal infection, and who likewise failed to respond to neuroleptics but responded to adrenocorticotrophic hormone and prednisone therapy. These case reports suggest a subgroup of patients with Tourette syndrome who may have symptoms triggered by streptococcal infection, and this group might respond to corticosteroid therapy. Many more patients with similar clinical profiles have been subsequently characterized, and many have been demonstrated, by prospective study, to have PANDAS. Additionally, detailed characterization of patients with Sydenham's chorea led to the discovery that many of these patients manifested symptoms of obsessive-compulsive disorder. These findings suggest a potential clinical overlap between Sydenham's chorea, tic disorders, and obsessive-compulsive disorder.

An antineuronal antibody was first identified in the circulation of patients with Sydenham's chorea by Zabriskie and coworkers over 30 years ago [6]. These Sydenhamassociated antineuronal antibodies or their targets still have not been characterized apart from qualitative properties. When compared with patients with rheumatic fever who did not have chorea, patients with chorea more commonly had antibodies in their serum which both recognized cells within the subthalamic and caudate nuclei and were adsorbed by streptococcal cellular components. This observation is consistent with the notion of "molecular mimicry," i.e., spurious cross-reactivity between antigens in disease associated streptococci and brain proteins. Patients with chorea associated with other illnesses, such as hereditary chorea (i.e., Huntington's disease) and lupus chorea, had antibodies which also recognized cells in the caudate nuclei, but did not bind to streptococcal cellular components [3].

Recent evidence also suggests the presence of antineuronal antibodies in children with PANDAS, Tourette 
syndrome, or obsessive-compulsive disorder. Using a method similar to that used by Zabriskie to detect antineuronal antibodies in Sydenham's chorea (staining of brain sections with crude serum), Kiessling et al. demonstrated that patients with a variety of pediatric movement disorders (including Tourette syndrome, motor or vocal tics, chorea, and choreiform movements) manifested a level of staining comparable to that observed in Sydenham's chorea [7-9]. Of note, studies have detected no correlation of these antibodies with either clinical status or the presence or absence of antistreptococcal antibodies $[10,11]$, similar to our findings here. The biochemical nature of putative target brain antigens in either Sydenham's chorea, Tourette syndrome, or obsessive-compulsive disorder has also been a focus of recent investigations. Using overlay Western immunoblotting, two groups [11], including our own [12,13], have reported the association of antibodies to an 83-kilodalton protein (which we have termed ts83) and Tourette syndrome-obsessive-compulsive disorder. These results suggest that the antineuronal antibodies detected in these patients may be directed primarily to a small number of antigens. More work needs to be performed to determine the precise nature of these immune abnormalities, their specificity for Tourette syndrome and obsessive-compulsive disorder [14], and their possible role in the pathophysiology of these disorders. Our current results strongly suggest that, whatever the nature of these antibodies, they cannot be explained as a consequence of acute GABHS infection alone.

\section{References}

[1] Swedo SE, Leonard HL, Mittleman BB, et al. Identification of children with pediatric autoimmune neuropsychiatric disorders associ- ated with streptococcal infections by a marker associated with rheumatic fever. Am J Psychiatry 1997;154:110-2.

[2] Swedo SE, Leonard HL, Garvey M, et al. Pediatric autoimmune neuropsychiatric disorders associated with streptococcal infections: Clinical description of the first 50 cases. Am J Psychiatry 1998;155:264-71.

[3] Husby G, van de Rijn I, Zabriskie JB, Abdin ZH, Williams RC, Jr. Antibodies reacting with cytoplasm of subthalamic and caudate nuclei neurons in chorea and acute rheumatic fever. J Exp Med 1976;144:1094110.

[4] Kondo K, Kabasawa T. Improvement in Gilles de la Tourette syndrome after corticosteroid therapy. Ann Neurol 1978;4:387.

[5] Matarazzo EB. Tourette's syndrome treated with ACTH and prednisone: Report of two cases. J Child Adolesc Psychopharmacol 1992;2:215-26.

[6] Zabriskie JB. Streptococcal cross-reactive antigens in relation to rheumatic fever. Zentralbl Bakteriol 1970;214:339-51.

[7] Hoekstra PJ, Kallenberg CG, Korf J, Minderaa RB. Is Tourette's syndrome an autoimmune disease? Mol Psychiatry 2002;7:437-45.

[8] Giulino L, Gammon P, Sullivan K, et al. Is parental report of upper respiratory infection at the onset of obsessive-compulsive disorder suggestive of pediatric autoimmune neuropsychiatric disorder associated with streptococcal infection? J Child Adolesc Psychopharmacol 2002; 12:157-64.

[9] Kiessling LS, Marcotte AC, Culpepper L. Antineuronal antibodies in movement disorders. Pediatrics 1993;92:39-43.

[10] Laurino JP, Hallett J, Kiessling LS, Benson M, Pelletier T, Kuhn C. An immunoassay for anti-neuronal antibodies associated with involuntary repetitive movement disorders. Ann Clin Lab Sci 1997;27: $230-5$.

[11] Singer HS, Giuliano JD, Hansen BH, et al. Antibodies against human putamen in children with Tourette syndrome. Neurology 1998; 50:1618-24.

[12] Trifiletti RR, Bandele A. TS83: Candidate target brain autoantigen in Tourette Syndrome and OCD. Ann Neurol 1998;44:561.

[13] Trifiletti RR, Bolen E, Bendele A. Changes in anti-neuronal antibodies following conventional and immunosuppressive therapy for Tourette Syndrome and OCD. Ann Neurol 1998;44:561.

[14] Morshed SA, Parveen S, Leckman JF, et al. Antibodies against neural, nuclear, cytoskeletal, and streptococcal epitopes in children and adults with Tourette's syndrome, Sydenham's chorea, and autoimmune disorders. Biol Psychiatry 2001;50:566-77. 